\title{
Espinho Planetarium's Public Outreach on Light Pollution
}

\author{
Lina Canas, Pedro B. Silva and Antonio Pedrosa \\ Navegar Foundation, Centro Multimeios Espinho, Av. 24, n800, 4500-202 Espinho, Portugal \\ email: lina.canas@multimeios.pt, pedro_silva@multimeios.pt, apedrosa@multimeios.pt
}

\begin{abstract}
Navegar Foundation has dedicated the past twelve years to astronomy public outreach by engaging the community in activities provided by the planetarium and observatory. The activities developed range from exhibitions to telescope observing sessions and planetarium shows. Whether partnering with local entities or with a variety of joint national and international activities, Navegar always had a proactive policy on raising awareness of light pollution issues. The outcomes of these activities are discussed.
\end{abstract}

Keywords. planetarium, observatory, light pollution

\section{Planetarium: an oasis in the urban centers}

Through our years of experience we have effectively used the planetarium to show the potential of a true night sky to schools and general population from urban areas in the northern region of Portugal. Located near sites of great population density centers and surrounded by an increasingly brighter night sky, the planetarium reveals itself as a unique vehicle to show how a true sky can be.

On direct feedback received from our visitors we can infer that although there is a true sense of awe from the audience when the star field is on, the sense of recognition of what the real sky is like is regarded more and more as science fiction! Many actually think that there are no such places on Earth where we actually see the sky as shown in the Planetarium. Younger audiences have no recollection of ever seeing the night sky like that. Older audiences regard it like a faraway memory and not as a present experience.

International campaigns and dedicated light pollution awareness events [2][3][4] prove to be effective contributors to raise and increase the interest of the community to light pollution issues. The sense of common goal and belonging to a worldwide campaigns, effectively draw attention. Another solution encountered was to relate light pollution problems to other sciences such as biology [1] and chemistry. Interlinking astronomy to other subjects proves to be a major asset in increasing the attendance number and raising global awareness, as this is a problem that the community can relate to beyond astronomy, and be more sensitive to wildlife impact problems or even health issues. Finally, there is a need of a constant and steady policy in introducing this subject on a regular basis to lead to habit change. The planetarium here proved and still proves to be one of the most powerful of tools to help us all remember the true sky and to strengthen the movement to reclaim the right to a real and a true dark sky for all.

\section{References}

Kwok, S. 2001, Cosmic Butterflies: The Colorful Mysteries of Planetary Nebulae, Cambridge University Press

GLOBE at Night. http://www.globeatnight.org/ (accessed July 27, 2012).

Dark Skies Awareness. http://www.darkskiesawareness.org/ (accessed July 27, 2012).

GAM Dark Skies Awareness Programs. Astronomers Without Borders. http://astronomerswithoutborders .org/gam2012-programs/dark-skies-awareness . html (accessed July 28, 2012). 